\title{
O analiză diacronică a cîmpului hidronimului $\mathrm{Crasna}^{\dagger}$
}

\author{
Daniela Butnaru* \\ Institutul de Filologie Română „A. Philippide”, Str. Th. Codrescu 2, 700481 Iași, România
}

\section{Despre articol \\ Istoric: \\ Primit 23 iulie 2018 \\ Cuvinte-cheie: \\ cîmp toponimic \\ polarizare \\ diferențiere \\ diacronie \\ Crasna}

Acceptat 21 august 2018

Publicat 7 octombrie 2018

\begin{abstract}
Rezumat
Ne-am propus, în acest articol, să urmărim formarea (prin procese structurale de polarizare și diferențiere, teoretizate de Dragoș Moldovanu) și evoluția în timp a cîmpului toponimic dezvoltat de la hidronimul Crasna, numele unui afluent al rîului Bîrlad. Organizarea unui astfel de ansamblu toponimic în jurul unui toponim principal, care desemnează un obiect (socio)geografic considerat de denominatori ca fiind de importanță majoră față de altele dintr-o zonă, este un proces natural, care oglindește realitatea de pe teren. Demersul nostru se sprijină pe informații culese din colecții de documente, dicționare, hărți și monografii. Prin urmărirea sincronică și diacronică a cîmpului hidronimului Crasna am surprins relațiile dintre toponime, concurența denominativă, existența unor omonimii și evoluția structurii toponimice.
\end{abstract}

\section{Introducere}

În acest articol, intenționăm să urmărim cum s-a format, în urma proceselor structurale de polarizare și diferențiere, un bogat cîmp toponimic dezvoltat în jurul Crasnei, numele unui afluent al rîului Bîrlad avînd $63,8 \mathrm{~km}$ lungime și un bazin hidrografic care se desfășoară pe $564 \mathrm{de} \mathrm{km}^{2}$ în interiorul județelor Iași și Vaslui (Ujvári, 1972, p. 504). Vom arăta, de asemenea, cum au evoluat în timp numele topice, atît din punctul de vedere al obiectelor denotate, cît și din perspectiva expresiei. Toponimele analizate în aceste pagini au fost excerptate din colecții de documente, dicționare, hărți și monografii.

\section{Cîmp toponimic, polarizare și diferențiere}

Cîmpurile toponimice sînt ansambluri de nume de locuri formate de către denominatori plecînd de la niște toponime-nucleu care desemnează obiecte (socio)geografice importante dintr-o zonă. „Elementul comun al grupului polarizat este numele acelui element central; distincțiile se fac prin entopice în funcție toponimică” (Moldovanu, 1972, p. 81). Polarizarea este procesul de creare a unor derivate toponimice care desemnează obiecte învecinate aparținînd unor clase geografice diferite, în timp ce prin diferențiere sînt desemnate părți ale aceluiaşi obiect geografic (Moldovanu, 2010, p. 18-19) ${ }^{1}$. Observarea numelor de locuri în cadrul cîmpurilor toponimice poate aduce informații despre raportul dintre nume și obiectul desemnat, asupra legăturii între diverse toponime, cît și asupra unor toponime dispărute. Crearea numelor de locuri plecînd de la alte toponime a fost observată și de Bolocan (1977), care a vorbit de transfer toponimic, sau de Rezeanu (2014, p. 19), care a propus termenul de extensie toponimică derivațională.

${ }^{\dagger} \mathrm{O}$ versiune anterioară a acestui text a fost prezentată sub formă de comunicare la simpozionul „Toponimia între istorie, geografie și lingvistică”, Iași, 10 mai 2018.

*Adresă de corespondență:d_butnaru@yahoo.com.

${ }^{1}$ Detalii despre teoria cîmpurilor toponimice, însoțite de numeroase exemple, se găsesc și în introducerea la MDTM. 


\section{Toponimul primar}

Cîmpul are în centru un toponim primar (nucleu), de la care se formează toponime derivate /secundare care îl conțin în structura lor. O etapă indispensabilă pentru stabilirea nucleului polarizator este identificarea etimologiei toponimice. În ceea ce privește toponimele Crasna, frecvente pe teritoriul românesc, există două direcții.

Conform unor istorici și lingviști, înțelesul numelui ar fi 'roșu'. Așa afirmă, de exemplu, Gh. Ghibănescu în Schiță istorică despre Vaslui, cu care începe volumul al XV-lea al colecției Surete și izvoade: „Crasna (sl. красенъ, красніи) roș. Deci apa Roșia” (Ghibănescu, 1926, p. III). Și Emil Petrovici, bun cunoscător al limbilor slave, consideră că echivalentul românesc al Crasnei este Roşia (1970, p. 248).

Alți lingviști au propus sensul de 'frumos' pentru adjectivul care stă la baza toponimului de faţă. Iorgu Iordan (1963, p. 113) face trimitere la v. sl. krasinŭ 'frumos', bulg. krasen 'frumos, drăguț' și sl. krasa 'frumusețe'. Nicolae Drăganu (1933, p. 476) indică proveniența din sl. krasbnz 'speciosus', 'amœnus'. Într-un articol despre tendința cancelariilor domnești de a slaviza numele de locuri, Alexandru I. Gonța merge mai departe și afirmă că numele Crasna ar fi de fapt traducerea toponimului românesc de către diecii moldoveni și ar trebui să fie citit în documentele medievale Pîrîul Frumos (Gonța, 1977, p. 264). Mircea Ciubotaru atrage însă atenția că folosirea acestui toponim pentru ilustrarea fenomenului de slavizare oficială medievală este greșită, hidronimul fiind „de origine slavă veche” (1992, p. 459), și că acesta va fi avut sensul, „mai vechi”, de 'frumos' (Ciubotaru, 2001, p. 60)².

Ambele sensuri ale etimonului par verosimile din punctul de vedere al motivării geografice. Studiile privind compoziția solului din regiunea străbătută de acest pîrîu susțin compoziţia preponderent argiloasă a terenului (Gugiuman et al., 1988, p. 61), care ar putea conferi un aspect roșiatic apei, în perioadele cînd aceasta este limpede. Pe de altă parte, documentele din vechime arată că în bazinul inferior și cel mijlociu al Crasnei existau numeroase sate, cu iezere, mori, prisăci, pometuri, vii și grădini (DRH, A, III, p. 254; VIII, p. 104-105; IX, p. 178, 314-315; XIX, p. 561-562; CDM, IV, p. 301 ș.a.), deci zona era favorabilă locuirii și exploatării agricole. Un „pîrîu frumos” este considerat unul „care are gura și malurile în pantă dulce, pe care se poate locui sau lucra în bune condițiuni” (Moldovanu, 2010, p. 145).

După legenda locală, numele moșiei Crasna ar proveni de la un oștean al lui Ștefan cel Mare, Crasnaș, ai cărui urmaşi au împărțit proprietatea în trei: Crăsniţa, Brădicești și Dolhești (MDG, III, p. 169)3.

\section{Derivate toponimice}

Atestat pentru prima dată într-o copie a unui document redactat probabil la 1 mai 1406 (DRH, A, I, p. 28), acest hidronim a devenit nucleul unui cîmp toponimic alcătuit din mai multe toponime secundare/derivate care desemnează obiecte (socio)geografice aflate în bazinul hidrografic al Crasnei. De la toponimul principal se formează derivate de gradul I de la care pot rezulta alte toponime-derivate de gradul al II-leaș.a.m.d. Prezentînd elementele componente ale acestui ansamblu toponimic, care pot fi urmărite și în Anexă, vom înfățișa și unele dintre problemele pe care le-am întîmpinat în încercările de a reconstitui cîmpul și de a stabili relațiile dintre numele de locuri care îl alcătuiesc.

Crasna al cărui nume îl analizăm în articolul de față se varsă în rîul Bîrlad într-o zonă a cărei denumire s-a format prin diferențiere toponimică: Gura Crasnei, consemnată la 1586 (DRH, A, VIII, p. 104). În acest loc a existat, în prima jumătate a secolului al XIX-lea, o staţie de poștă cu același nume-Gura Crasnei-, lîngă care se va înființa treptat un sat omonim, atestat pentru prima dată la 1871 (TTRM, $\mathrm{I}_{1}$, p. 308). Spre sfirșitul secolului al XIX-lea aici a fost construită o gară în vederea deservirii căii ferate Crasna-Huşi, dată

\footnotetext{
${ }^{2}$ Vezi și Vasmer (1967, p. 368; din v. sl. krasınz 'speciosus, perpulcher, iucundus, amœnus'), Grinčenko (1925, p. 836; Красинй 'minunat, frumos, bun'). Cf. subst. kpaca 'venustas, pulchritudo' (Miklosich, 1927, p. 269; 1862, p. 309; Śmilauer, 1970, p. 100).

${ }^{3}$ De la un antroponim Crasnăș, atestat în documente din secolele XV-XVII (Gonța, 1995, p. 136-137), s-a format, de fapt, numele satului Crăsnășenii, situat tot pe pîrîul Crasna.
} 
în folosință în anul 1888 (Lupu \& Kalinca, 1990, p. 1), fapt care a condus la apariția, în unele documente ale timpului, a denumirii Gara Crasnei (ibidem) sau, cu determinantul la nominativ, Gara Crasna (Chiriță, 1893, p. 83). Cele două sintagme apar alternativ în acte oficiale pînă în 1924, cînd satul va primi numele Crasna, aşa cum se numește și astăzi (TTRM, $\mathrm{I}_{1}$, p. 308).

Zona de la izvoarele acestei ape apare în documente vechi cu denumirea Obîrşia Crasnei (DIR, A, XVII, p. 221, în anul 1523) sau, cu alte entopice, Fundul Crasnei (Ghibănescu, 1913, p. 321, în anul 1668) și Fundătura Crasnei (CDM, III, p. 284, în anul 1666). În zona respectivă a existat o moșie Fundul Crasnei, pe care ulterior s-a înființat și un sat omonim (numit astăzi Rotăria, vezi infra).

În urma procesului de diferențiere toponimică s-a format, prin derivare cu sufixul diminutival -ița, hidronimul Crăsnița. Întîlnit și în sintagma Valea Crăsnița, acesta desemnează unul dintre primii afluenți pe dreapta ai pîrîului Crasna, în amonte de satul Dolhești din județul Iași (CDM, V, p. 202, anul 1708). Prin diferențiere toponimică a rezultat numele zonei de la izvoarele acestui pîrîu, Obîrșia Crăsniței (Merlan \& Hapaleț, 2006, p. 52), iar prin polarizare s-au format denumirile Dealul Crăsnița sau, cu determinantul la genitiv, Dealul Crăsniței, Pădurea Crăsnița (atlas mold.), Iazul Crăsnița (Merlan \& Hapaleț, 2006, p. 18) și Podişul Crăsniței (ibidem, p. 16). Pentru că în această zonă este atestată, în prima jumătate a secolului al XIX-lea, o moșie Crasna Seacă, lîngă satul Dolhești (v. TTRM, $\mathrm{I}_{1}$, p. 308), deducem că nu este exclus ca acest curs de apă să fi fost numit și Crasna Seacă.

În unele surse (de exemplu în HARTA MIL.) Crăsniţa desemnează cursul superior al Crasnei. De aici s-a format, prin diferențiere, denumirea pentru zona izvoarelor: Fundul Crăsniţei. Cele două numeCrasna și Crăsnița - au fost folosite chiar simultan pentru identificarea cursului superior al Crasnei, după cum o arată diverse documente sau hărți. De exemplu, moșia aflată în această zonă s-a numit în perioada 1825-1858 Crasna, Fundul Crasnei, Fundul Crăsniței sau Crăsnița (TTRM, I 2 , p. 1005); un schit situat în această zonă este menționat în timp ca Fundul Crasnei (тTrm, I2, p. 1005), Schitul de la Crăsniţa, Schitul Crăsnița ori Schitul din Crasna (vezi Costăchescu, 1924, p. 317, 319, 320) ${ }^{4}$. Pe moșia mai sus menționată s-a format satul Rotăria de astăzi, atestat, de-a lungul timpului, cu denumirile Rotarul sau Rotarul din Fundul Crasnei, Rotarii, Crăsnița, Crasna și Fundul Crasnei (Ttrm, $\mathrm{I}_{2}$, p. 1005).

Într-un act de la 1535 este menționat satul Zavalnești, pe Crăsnișoara, sat aflat în apropiere de actuala localitate Gugești din Vaslui (DIR, A, XVI-I, p. 378), iar într-un document din 1594 este atestat satul Liești, situat „între Crasna și Crăsnișoara” (DRH, A, IX, p. 178); el nu mai există astăzi, dar numele său a fost păstrat de toponimul Valea Liești (ROM., 40). Din informațiile cuprinse în aceste două documente se poate concluziona că hidronimul Crăsnişoara (format prin derivare cu sufixul diminutival -işoara) indică un alt afluent drept al pîrîului Crasna, probabil cel numit astăzi Pîrîul Bălțaţi, după numele satului aflat pe cursul său ${ }^{5}$. Prin procesul de diferențiere toponimică s-a denumit zona de la izvoare: Obîrșia Crăsnişoarei (DIR, A, XVI-I, p. 221). Același afluent este desemnat, trei ani mai tîrziu, cu varianta Crăsnița (DRH, A, IX, p. 315).

Derivatele diminutivale atestate de-a lungul timpului desemnează atît cursul superior al pîrîului, cît și mai mulți afluenți ai acestuia, reflectînd o modalitate denominativă populară, întîlnită și în cazul altor cursuri de apă (Bistrița, Bîrlad etc.). Intervenția reprezentanților administrației și a geografilor în procesul de denominație a avut ca rezultat impunerea altor denumiri pentru unii afluenți, formate de obicei de la numele satelor pe care acele ape le străbat.

Am identificat mai multe dealuri, aflate în apropierea acestui curs de apă, al căror nume intră în componența cîmpului toponimic aflat în discuție: un deal în bazinul superior al pîrîului Crasna, lîngă satul Rotăria (ROM., 40), un altul la vest de satul Armăşeni (MDG, I, p. 119), unul la vest de orașul Huși (CDM, V, p. $203^{6}$ ) și unul între Crasna și Lohan (ATLAS MOLD.). Probabil și din cauza polionimiei Crasna/Crăsniţa

\footnotetext{
${ }^{4}$ De la numele acestui locaș religios s-a format, prin polarizare, un hidronim: Pîrîul Schitului, numele unui afluent drept al Crasnei în aval de satul Pietriș, județul Vaslui (Costăchescu, 1924, p. 318).

${ }^{5} \mathrm{Nu}$ este exclus nici ca acest afluent să fie Pîrîul Burghina de astăzi, aflat mai la sud de Pîrîul Bălțați.

${ }^{6} \mathrm{O}$ dovadă că aceste oronime s-au format prin polarizare de la hidronim o constituie atestarea sintagmei toponimice Dealul Văii Crasnei (pentru desemnarea dealului din hotarul tîrgului Huși) într-un document de la 1705 (CDM, V, p. 107). Ulterior,
} 
au apărut erori la reprezentarea pe hărți a cîtorva obiecte geografice formate de la aceste denumiri. Dacă majoritatea surselor indică prezența Dealului Crăsniţa pe dreapta rîului Crasna, lîngă pîrîul Crăsnița, de la care își va fi luat și numele, iar Dealul Crasna apare pe stînga cursului de apă, în HARTA MIL. din 1962 cele două dealuri sînt reprezentate inversat; și în MDG (III, p. 169) colina de lîngă pîrîul Crăsnița este numită Dealul Crasna. De la oronimul Dealul Crasna care desemnează un deal situat în apropiere de izvorele Crasnei, s-au format, prin diferențiere, denumirile Culmea Dealului Crasna, Muchia Crasna (ATlas MOld.) și Pădurea Dealului Crasna (Merlan \& Hapaleț, 2006, p. 113).

După cum am arătat, de la numele pîrîului Crasna s-au format și numele unor sate și moșii; în afară de satul aflat la confluența cu rîul Bîrlad și de cel aflat la izvoare, numit astăzi Rotăria, am identificat două moșii ale căror nume intră în complexul denominativ format în jurul hidronimului Crasna. În DRH, A, XX există cîteva documente din prima jumătate a secolului al XVII-lea în care se menționează o Crasna pe care editorii volumului o consideră ca fiind localitatea Crasna din zona de vărsare a pîrîului Crasna în Bîrlad (DRH, A, XX, p. 769). Însă, o lectură atentă a documentelor (DRH, A, XX, p. 193, 212-213 și 358) și urmărirea hotarelor satului Broșteni, la care se referă deciziile din acele acte, conduc la concluzia că este vorba de o altă moșie Crasna, aflată la vest de orașul Huși ${ }^{7}$. În confirmarea acestei ipoteze vine o informație din Caproșu (2000, p. 359): doi greci grădinari, un cojocar rus și doi foști robi „șăd la Crasna, în satul Tătărani”; TTRM, $\mathrm{I}_{1}$, p. 312 atestă existența în această zonă a unui trup de moșie Crasna (care la 1907 va fi inclus în moșia satului Crețești din județul Vaslui). La Rîpele Crasnei, unde s-au așezat la 1742 niște bejenari fugiți din satul Băhnarii (Mihordea, 1961, p. 265), trebuie să fi fost o altă moșie în bazinul mijlociu al Crasnei.

După cum dovedesc documentele, de-a lungul timpului, pe Crasna au fost multe iazuri, unul dintre ele fiind atestat la 1493 în perifraza Iezerul de la Crasna (în original шзерА нА краснои, DRH, A, III, p. 254, anul 1493), în apropiere de actualul sat Tălpigeni din Vaslui. Un alt toponim din cîmpul prezentat în aceste pagini este Pădurea Crasnei (MDg, II, p. 41) sau Codrul Crasnei (Giurescu, 1967, p. 40) ${ }^{8}$. Dintre toponimele secundare formate de la hidronimul Crasna mai amintim: S,esul Crasnei (TEZ.vAs., p. 132; MDG, II, p. 750 și V, p. 553), Podul peste Crasna (Chirica \& Tanasachi, 1984, p. 129), Piscul Crasnei și Drumul Crasnei (cDm, V, p. 239), Lunca Pîrîului Crasna (Merlan \& Hapaleț, 2006, p. 11), Microdepresiunea Crasna și Podişul Crasnei (ultimele două fiind denumiri livrești, geografice).

Acest cîmp toponimic include și cele două horonime Ocolul Crasna, care desemnau unități administrative din ținuturile Vasluiului, respectiv Fălciului cuprinzînd fiecare mai multe localități situate în bazinul hidrografic al Crasnei (TTRM, I 2 , p. 1432-1434).

\section{Aspecte morfosintactice}

Toponimul-nucleu este întîlnit de multe ori în forma simplă, avînd entopicul ce indică clasa geografică (apă, pîrîu, vale) inclus în conţinutul său. Îl întîlnim totuşi, de-a lungul timpului, și în sintagme cu determinantul la genitiv (Apa Crasnei DIR, A, XVI-II, p. 114; Pîrîul Crasnei DRH, A, VI, p. 170; Valea Crasnei MDG, II, p. 747) sau la nominativ (Apa Crasna CDM, IV, p. 439; Pîrîul Crasna DRH, A, XXII, p. 72; Valea Crasna MDG, IV, p. 37, chiar, prin supraaprecierea calităţii cursului de apă, Rîul Crasna, Merlan \& Hapaleț, 2006, p. 10). În hărți redactate în limbi străine, numele acestui curs de apă apare frecvent în semicalcuri: Krasna Fl[euve] (anul 1781), Krasna Riv[ière] (anul 1696), Knisna Fl[uss] (anul 1788), Krasna Fl[uss] (anul 1787), Krasna F[iume] (anul 1788), Krasna Fl[uvius] (anul 1774), Crasna R[eka] (în 1772), R[eka] Cracni (anul 1774) (vezi TTRM, I, p. 63).

a avut loc o simplificare a denumirii la Dealul Crasnei.

${ }^{7}$ Un martor la vînzarea unei părți de moșie pe Crasna, ținutul Fălciu, alături cu hotarul Stroieștilor, deci tot la vest de localitatea Huși, era, la 1691, Postolache Coșescul din Crasna (TEZ.VAS., p. 55).

${ }^{8}$ Pădurea este menționată chiar în Analele cronicarului polonez Jan Długosz, „,in silva post villam Krassne”, alături de pîrîu şi cîmpia străbătută de acesta: „in campo, qui Krasnepolye appellatur, ad torrentem Krasni potok” (apud Antoche, 2013 , p. 16 şi 19). 
Cîmpul toponimului Crasna cuprinde nume topice simple, derivate sau complexe ${ }^{9}$. Simple sînt toate oiconimele Crasna, care vor fi rezultat, printr-un proces de simplificare, din perifrază ( ${ }^{*}$ Satul depe Crasna) sau sintagmă ( ${ }^{*}$ Satul Crasna). Toponimele obținute prin procedeul derivării sînt Crăsnița și Crăsnișoara; derivarea cu sufixe diminutivale este specifică procesului de diferențiere toponimică, și exprimă opoziția „curs principal” - „afluent” sau „curs principal” - „curs superior”.

Cele mai multe denumiri rezultate în urma polarizării sînt de obicei sintagme, „cu un determinant unic, și anume toponimul primar, și cu determinate multiple, reprezentînd termeni care desemnează clasa de obiecte geografice" (Moldovanu, 2010, p. 18). Toponimele sintagmatice din cîmpul hidronimului Crasna nu fac excepție: Dealul Crăsniţa, Pădurea Crasnei, Rîpele Crasnii, Șesul Crasnei etc. Nu lipsesc din cîmp elementele cu structură perifrastică: Iezerul de la Crasna, Podul peste Crasna, Schitul de la Crăsnița. Și în urma diferențierii toponimice pot rezulta sintagme, desemnîndu-se, cu ajutorul unor delimitatori lexicali, părți ale obiectului geografic denumit (Moldovanu, 2010, p. 19): Dealul Crasna - Culmea Dealului Crasna, Crasna - Gura Crasnei, Crăsnița - Fundul Crăsniței.

$\mathrm{Cu}$ excepția cîtorva denumiri livrești, specifice registrului științific geografic, elementele care compun structura toponimică dezvoltată în jurul hidronimului Crasna sînt formate prin procedee tipice pentru toponimia populară românească.

\section{Concluzii}

Cîmpul toponimic format în jurul toponimului-nucleu Crasna este unul bogat și divers din punct de vedere al tipurilor de denumiri rezultate în urma proceselor structurale de polarizare și diferențiere (precedee teoretizate de Dragoș Moldovanu). Adunînd nume de locuri și informaţii din colecții de documente, dicționare, hărți și monografii, am reușit să surprindem complexitatea acestui ansamblu denominativ, evoluția toponimelor și relațiile dintre ele, prezența unor omonimii și concurența denominativă. Analiza morfosintactică a arătat că, exceptînd cîteva denumiri livrești, geografice, toate toponimele din acest cîmp sînt formate prin procedee tipice pentru toponimia populară românească. În Anexă am prezentat într-o manieră schematică acest ansamblu denominativ format din derivate toponimice de diverse grade dezvoltate de la hidronimul polarizant Crasna.

\section{Bibliografie}

\section{A. Lucrări de referință}

Antoche, E. C. (2013). Lexpédition polonaise de 1450 en Moldavie et la bataille de la petite rivière de Crasna (Izvorul Crasnei, 6 septembrie 1450), în „Rocznik Przemyski”, 49, p. 3-24.

Bolocan, Gh. (1977). Transferul de nume în toponimie, în „Studii și cercetări lingvistice”, XXVIII, nr. 2, p. 171-180.

Caproșu, I. (2000). Documente privitoare la istoria orașului Iași, Editura Dosoftei, Iași.

Chirica, V. \& Tanasachi, M. (1984). Repertoriul arheologic al județului Iaşi, vol. I, Iași.

Chiriță, C. (1893). Dicționar geografic al județului Fălciu, Tipografia Petru C. Popovici, Iași.

Ciubotaru, M. (1992). [recenzie la] Alexandru I. Gonța, Documenteprivind istoria României. A. Moldova. Veacurile XIV-XVII (1384-1625). Indicele numelor de locuri, Editura Academiei Române, București, 1990, în „Anuarul Institutului de Istorie «A.D. Xenopol»", XXIX, 1992, p. 457-459.

Ciubotaru, M. (2001). Oronimia și hidronimia din bazinul superior al Bîrladului, Casa Editorială Demiurg, Iași.

Costăchescu, M. (1924). Schitul de la Crăsnița (Vaslui), în „Ion Neculce”, IV, p. 317-320.

Drăganu, N. (1933). Românii în veacurile IX-XIV pe baza toponimiei și a onomasticei, Imprimeria Națională, București.

Ghibănescu, Gh. (1913). Surete și izvoade. Vol. VIII, Tipografia „Dacia” P\&D. Iliescu, Iași.

Ghibănescu, Gh. (1926). Surete și izvoade. Vol. XV. Vasluiul. Studiu și documente, Institutul de arte grafice „Viața românească”, Iași.

\footnotetext{
${ }^{9}$ Prin toponime complexe ne referim la numele de locuri formate din mai mulți termeni: perifraze și sintagme toponimice sau toponime compuse. Prin folosirea acestui termen ne delimităm de majoritatea lucrărilor de toponimie care consideră a fi compuse toate toponimele formate din mai multe cuvinte, și nu doar cele care, la fel ca substantivele comune, ar trebui să aibă „anumite particularități flexionare ce decurg din pierderea totală sau parțială a autonomiei tuturor termenilor constitutivi sau doar a unora dintre aceștia” (GLR, I, I, p. 92). Pentru o discuție detaliată despre acest subiect, vezi Moldovanu (1991, p. LIX).
} 
Giurescu, C.C. (1967). Istoria pădurii românești din cele mai vechi timpuri pînă astăzi, Editura Ceres, București.

Gonța, Al. (1977). Rolul cancelariei moldovenești în slavizarea numelor de locuri în secolele XIV-XVI (Originea istorică a Cobîlelor), în „Anuarul Institutului de Istorie și Arheologie «A.D. Xenopol»”, XIV, p. 261-275.

Gonța, Al. (1995). Documente privind istoria României. A. Moldova. Veacurile XIV-XVII (1384-1625). Indicele numelor de persoane, Editura Academiei Române, București.

Grinčenko, B.D. (1925). Slovar' ukrainskogo jazyka, Derjavne Vidavnițvo Ukraini, Kiev.

Gugiuman, I., Cîrcotă, V. \& Baican, V. (1988). Dicționar geografic al județului Vaslui, Centrul de multiplicare al Universității „Alexandru Ioan Cuza”, Iași.

Iordan, I. (1963). Toponimia românească, Editura Academiei, București.

Lupu, I. \& Kalinca, R. (1990). Linia ferată Crasna-Huşi. O sută de ani. (15 X 1890-15 X 1990). Completări monografice, Regionala Căii Ferate, Iași.

Merlan, V. \& Hapaleț, G. (2006). Monografia comunei Dolhești, județul Iaşi. 666 de ani de atestare documentară, Iași, Editura Lumen.

Mihordea, V. (1961). Documente privind relațiile agrare în veacul al XVIII-lea, vol. II, Editura Academiei, București.

Miklosich, Fr. (1862-1865). Lexicon paleoslovenico-graco-latinum emendatum auctum, Guilelmus Braumueller, Viena.

Miklosich, Fr. (1927). Die Bildung der slavischen Personen- und Ortsnamen, Carl Winters Universitätsbuchhandlung, Heidelberg.

Moldovanu, D. (1972). Principii ale lexicografiei toponimice, în „Anuar de lingvistică și istorie literară”, XXIII, p. 73-100.

Moldovanu, D. (1991). Introducere la TTRM, $\mathrm{I}_{1}$.

Moldovanu, D. (2010). Teoria cîmpurilor toponimice (cu aplicație la cîmpul hidronimului Moldova), Editura Universității „Alexandru Ioan Cuza”, Iași.

Petrovici, E. (1970). Studii de dialectologie și toponimie, Editura Academiei, București.

Rezeanu, A. (2014). Periplu toponimic, Editura Academiei Române, București.

Šmilauer, V. (1970). Handbuch der slawischen Toponomastik, Československé akademia věd, Praga.

Ujvári, I. (1972). Geografia apelor României, București, Editura Științifică.

Vasmer, M. (1967). Etimologičeskij slovar' russkogo jazyka (traducere și completări de O.N. Trubačev), II, Izdatelstvo Progress, Moskva.

\section{B. Sigle}

ATLAS MOLD. = Institutul Geografic al Armatei, Atlasul Moldovei (1:50 000), București, 1892-1898.

$\mathrm{CDM}=$ Catalogul documentelor moldovenești din Arbiva Istorică Centrală a Statului, I (1387-1620), II (1621-1652), III

(1653-1675), IV (1676-1700), V (1701-1720), București, 1957, 1959, 1968, 1970, 1975.

DIR, A = Documente privind istoria României. A. Moldova, Editura Academiei, București, 1951-1957.

DRH, A = Documenta Romanie Historica. A. Moldova, I-XXVII, București, 1975-2006.

GLR, I = Gramatica limbii române. I. Cuvîntul, Valeria Guțu Romalo (coord.), București, Editura Academiei Române, 2005.

HARTA MIL. = Harta R.S. România, executată de Direcția Topografică Militară, (1:25 000), București, 1962.

MDG = George Ioan Lahovari (coord.), Marele dicționar geografic al României, I-V, Socec, București, 1898-1902.

MDTM = Mic dicționar toponimic al Moldovei, structural și toponimic. Partea I. Toponime personale, Dragoș Moldovanu (coord.),

Editura Universității „Alexandru Ioan Cuza”, Iași, 2014.

ROM. = România. Atlas rutier, de general maior ing. Vasile Dragomir, col. ing. Victor Balea, col. ing. Gheorghe Mureșanu,

Gheorghe Epuran (sc. 1:350 000), Editura Flomarco, București, 1981.

TEZ.vAs. = Din tezaurul arhivistic vasluian. Catalog de documente, 1399-1877, întocmit de Grigore Găneț și Costică-Ioan Gârneață, București, 1986.

TTRM, $\mathrm{I}_{1-2}=$ Tezaurul toponimic al României. Moldova. $\mathrm{I}_{1-2}$, Repertoriul istoric al unităţilor administrativ-teritoriale (17721988), Dragoș Moldovanu (coord.), București, 1991-1992.

TTRм, $\mathrm{I}_{4}=$ Tezaurul toponimic al României. Moldova. $\mathrm{I}_{4}$, Toponimia Moldovei în cartografia europeană veche (cca 1395-1789),

Dragoș Moldovanu (autor), Iași, 2005. 


\section{Anexa A. Cîmpul toponimic Crasna}

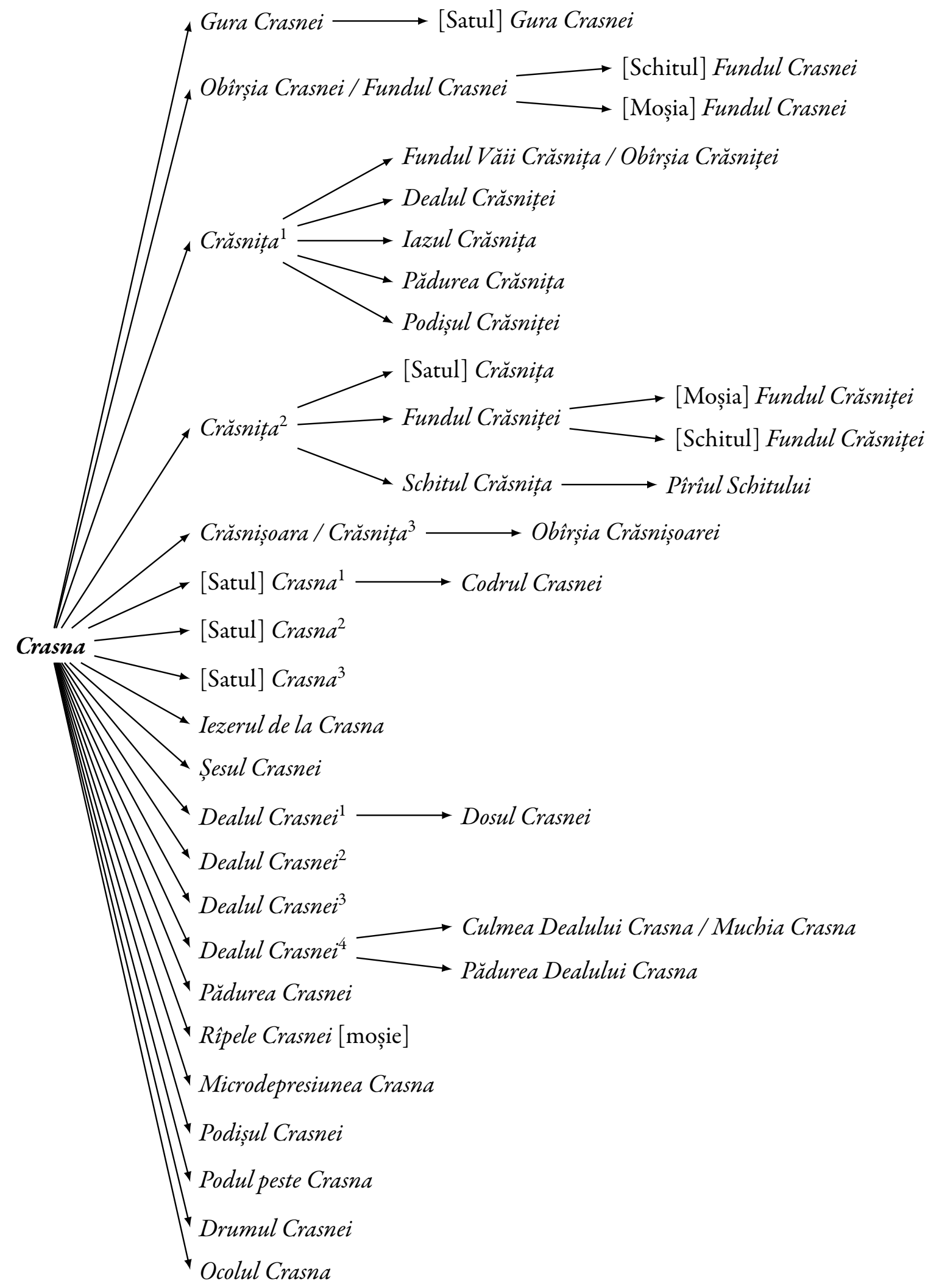

